
www.sba.com.br/rba/index.asp

\title{
Malignant Hyperthermia in Brazil: Analysis of Hotline Activity in 2009
}

\author{
Helga Cristina Almeida da Silva* 1 , Clea dos Santos Almeida ${ }^{2}$, \\ Julio Cézar Mendes Brandão ${ }^{3}$, Cleyton Amaral Nogueira e Silva ${ }^{3}$, \\ Mariana Elisa Pinto de Lorenzo ${ }^{3}$, Carolina Baeta Neves Duarte Ferreira ${ }^{3}$, \\ André Hosoi Resende ${ }^{3}$, Sara Rocha Barreira ${ }^{3}$, Priscilla Antunes de Almeida ${ }^{3}$, \\ Leonardo Henrique Cunha Ferraro ${ }^{3}$, Alexandre Takeda ${ }^{3}$, Kátia Ferreira de Oliveira ${ }^{3}$, \\ Talitha Gonçalez Lelis ${ }^{3}$, Alexandre Hortense ${ }^{4}$, Marcelo Vaz Perez ${ }^{5}$, Beny Schmidt ${ }^{6}$, \\ Acary Souza Bulle Oliveira ${ }^{6}$, José Luiz Gomes do Amaral ${ }^{7}$
}

1. MD; PhD; Professor; Department of Anesthesiology, Pain and Intensive Care, Escola Paulista de Medicina, Universidade Federal de São Paulo (Unifesp)

2. RN; MSc Student, Department of Anesthesiology, Pain and Intensive Care, Escola Paulista de Medicina, Unifesp

3. MD; Department of Anesthesiology, Pain and Intensive Care, Escola Paulista de Medicina, Unifesp

4. MD; MSc; Department of Anesthesiology, Pain and Intensive Care, Escola Paulista de Medicina, Unifesp

5. MD; PhD, Department of Anesthesiology, Pain and Intensive Care, Escola Paulista de Medicina, Unifesp

6. MD; PhD, Professor, Division of Neuromuscular Diseases, Department of Neurology, Escola Paulista de Medicina, Unifesp

7. MD, PhD, Full Professor of Anesthesiology, Pain and Intensive Care, Escola Paulista de Medicina, Unifesp

Received from Centro de Estudo, Diagnóstico e Investigação de Hipertermia Maligna (Center of Study, Diagnosis and Investigation of Malignant Hyperthermia - Cedhima); Department of Anesthesiology, Pain and Intensive Care; Escola Paulista de Medicina, Universidade Federal de São Paulo (Unifesp), Brazil.

Submitted on August 22, 2011. Approved on March 12, 2012.

Keywords:

Adverse Drug Reaction Reporting Systems; Anesthetics/adverse effects; Intraoperative Complications;

Malignant

Hyperthermia.

\begin{abstract}
Background and objectives: Malignant hyperthermia $(\mathrm{MH})$ is a pharmacogenetic disease that causes abnormal hypermetabolic reaction to halogenated anesthetics and/or depolarizing muscle relaxants. In Brazil, there is a hotline telephone service for MH since 1991, available 24 hours a day in São Paulo. This article analyzes the activity of the Brazilian hotline service for MH in 2009. Methods: Prospective analysis of all phone calls made to the Brazilian hotline service for $\mathrm{MH}$ from January to December 2009.

Results: Twenty-two phone calls were received: 21 from the South/Southeast region of Brazil and one from the North region. Fifteen calls were requests for general information about $\mathrm{MH}$. Seven were about suspected $\mathrm{MH}$ acute episodes, two of which were not considered as $\mathrm{MH}$. In five episodes compatible with $\mathrm{MH}$, all patients received halogenated volatile anesthetics (2, isoflurane; 3 , sevoflurane) and one also used succinylcholine; there were four men and one woman, with a mean age of 18 years (2-27). The problems described in the five $\mathrm{MH}$ episodes were tachycardia
\end{abstract}

* Corresponding author: Rua Napoleão de Barros, 715/5ªndar

Vila Clementino 04024-002 - São Paulo, SP, Brasil.

E-mail: halsilva@uol.com.br 
(5), increased expired carbon dioxide (4), hyperthermia (3), acidemia (1), rhabdomyolysis (1), and myoglobinuria (1). One patient received dantrolene. All five patients with $\mathrm{MH}$ episodes were follow-up in the intensive care unit and recovered without sequelae. Susceptibility to MH was later confirmed in two patients by in vitro muscle contracture test.

Conclusions: The number of calls per year in the Brazilian hotline service for MH is still low. The characteristics of $\mathrm{MH}$ episode were similar to those reported in other countries. The knowledge of $\mathrm{MH}$ in Brazil needs to be increased.

(c) 2013 Sociedade Brasileira de Anestesiologia. Published by Elsevier Editora Ltda. All rights reserved.

\section{Introduction}

Malignant hyperthermia $(\mathrm{MH})$ is a pharmacogenetic disorder with autosomal dominant inheritance, characterized by abnormal hypermetabolic response to inhalational anesthetics (halogenated group) and depolarizing muscle relaxants, such as succinylcholine ${ }^{1}$. Typical episodes feature tachycardia, tachypnea, hypercarbia, muscle rigidity, hyperthermia, metabolic acidosis, and rhabdomyolysis. However, there is great clinical variability, with abortive, atypical or fulminant forms, and even isolated masseter spasm ${ }^{1,2}$. MH also has genetic variation: approximately $50 \%$ to $70 \%$ of cases are associated with ryanodine receptor gene mutations (a calcium release channel from the sarcoplasmic reticulum into the cytoplasm of the muscle fiber), but mutations have been described in other genes related to calcium metabolism, such as the dihydropyridine receptor gene ${ }^{3,4}$. MH was first described in 1960 and occurs at frequencies up to $1: 10,000$ general anesthesias in children and 1:50,000 in adults ${ }^{2}$. The first report on $\mathrm{MH}$ in Brazil occurred during halothane anesthesia and was published in $1975^{5}$. However, there is no data on the actual incidence of $\mathrm{MH}$ in Brazil, a continental country with 190 million inhabitants ${ }^{5}$. Considering the 3,890,755 anesthesias performed at the Unified Health System (SUS) in 2009 and 1:50,000 frequency of $\mathrm{MH}$ episodes during general anesthesia in adults, one would expect at least 77 reports of $\mathrm{MH}$ episodes during this period ${ }^{6}$.

In 1991, a service for MH was created in Brazil called Hotline (+55-11-55759873), which is available 24 hours per day. The Brazilian hotline service for $\mathrm{MH}$ is located in the city of São Paulo at Hospital São Paulo, Escola Paulista de Medicina, Universidade Federal de São Paulo (EPM/Unifesp) ${ }^{7}$. Between 1991 and 2008, phone calls to the hotline were directed to the Division of Surgical Intensive Care and answered by the intensive care staff, assisted by MH supervisors. Since 2009, phone calls have been redirected to a group consisting of two supervisors - also specialized in $\mathrm{MH}$ investigation (HCAS, neurologist - and JLGA, anesthesiologist) - and eight doctors. The physicians received training that consisted of an intensive course on $\mathrm{MH}$, with theoretical and practical information. Training included dantrolene dissolution and diagnostic test for MH susceptibility, through in vitro muscle contracture test (IVCT) in response to halothane and caffeine, which is available at the Center for Study, Diagnosis and Investigation of Malignant Hyperthermia (Cedhima), Hospital São Paulo (EPM/Unifesp).

The objective of this study is to analyze the activity of the Brazilian hotline service for MH in 2009.

\section{Material and methods}

This was a prospective, analytical and observational study. The study's primary material was the attendance records of the Brazilian hotline service for MH in 2009. These attendance records consisted of data identifying the caller, call location (city, state, hospital service, or residence), return phone number, description of call reason, proposed solution, consultant identification, and date. For classification, two independent investigators analyzed each record. Initially, categorization and tabulation of data on call location, caller, description of call reason, and solution proposed were performed. For records in which the call reason was a suspected episode of $\mathrm{MH}$, we used a clinical scale described by Larach et al. ${ }^{8}$ to grade the likelihood of $\mathrm{MH}$. This scale should not be used to make a diagnosis of MH susceptibility, but serves to classify the severity of episodes. In this 1 - to 6-point scale (from almost incompatible to almost certain), $\mathrm{MH}$ suspected episodes are classified according to points obtained when analyzing the following variables: muscle rigidity, rhabdomyolysis, hyperthermia, cardiac abnormality, acid-base changes, and response to treatment with dantrolene ${ }^{8}$. The study secondary material was the medical records of patients who, after being notified of the Brazilian hotline service for $\mathrm{MH}$ in 2009, were referred to Cedhima for evaluation/investigation and provided signed informed consent (CEP 0970/08). Data collected from medical records were demographic; medical, family, and epidemiologic history; current complaints; general physical examination; neurological examination; and laboratory tests, including histopathological study of muscle with histochemistry and in vitro muscle contracture test in response to halothane and caffeine. Histopathological study of muscle included the following reactions and staining: hematoxylin-eosin, periodic acid-Schiff (PAS), modified Gomori trichrome, Sudan black B; succino dehydrogenase (SDH), cytochrome C-oxidase (COX), nicotinamide adenine dinucleotide tetrazolium reductase (NADH), and adenosine triphosphatase (ATPase) acidic ( $\mathrm{pH}$ 4.3) and alkaline ( $\mathrm{pH} 9.4)$, according to the methodology described by Dubowitz ${ }^{9}$.

In vitro muscle contracture test in response to halothane and caffeine was performed according to the protocol of the European Malignant Hyperthermia Group (www.emhg.org) ${ }^{10}$. After biopsy, four fragments $(0.5 \times 2 \mathrm{~cm})$ of vastus lateralis muscle are immediately placed into a Krebs-Ringer's solution (95\% oxygen and 5\% carbon dioxide) and dissected into thin fragments (2-3 mm) under stereomicroscope (Olympus, USA). Then, each fragment is attached to a silver electrode at one 
end and to a force transducer at the other (transducer Narco Bio Systems, International Biomedical, USA). Tests are made in baths heated to $37^{\circ} \mathrm{C}$, through thermostatically controlled circulating water (Mecânica Castro Saraiva, Brazil), filled with Krebs-Ringer's solution and continuously carboxygenated. Each fragment is continuously stimulated with supramaximal electrical pulses of $1 \mathrm{~ms}$ and frequency of $0.2 \mathrm{~Hz}$ (Boeck stimulator). The degree of muscle contraction is monitored in real time during the entire test and detected by force transducer linked to an IBM 486 computer, using an amplifier/analog-digital converter and program for biological data acquisition AqDados (Links, Brazil). At least four tests are performed for each patient: two with caffeine and two with halothane. To test caffeine, concentrations of $0.5,1.0,1.5$, 2.0, 3.0, 4.0 and 32.0 mmol. $\mathrm{L}^{-1}$ are used. To test halothane, the concentrations are $0.5,1.0,2.0$ and $3.0 \%$. Test results are referred to as the threshold, which is the lowest concentration of caffeine and halothane producing a minimum increase of $0.2 \mathrm{~g}$ in basal tension.

According to test results, patients are classified into three groups:

a) Malignant hyperthermia susceptibility (MHS): caffeine threshold concentration of $2.0 \mathrm{mmol}$ or less and halothane threshold of $2.0 \%$ or less;

b) Malignant hyperthermia nonsusceptible (MHN): caffeine threshold concentration of $3.0 \mathrm{mmol}$ or more and halothane threshold of $3.0 \%$ or more;

c) Malignant hyperthermia equivocal (MHE): other results are considered equivocal.

From a practical standpoint, MHE patients are also considered susceptible to $\mathrm{MH}$.

\section{Results}

In 2009, the Brazilian hotline service for $\mathrm{MH}$ received 22 calls: 21 from the South/Southeast region and one from the North region (Pará State). The Southeast region had 17 calls, all from the State of São Paulo, and the Southern region had four calls, three from Paraná and one from Rio Grande do Sul.

Among the 22 calls, 15 were requests for general information about $\mathrm{MH}$ and seven about suspected $\mathrm{MH}$ acute episodes. General information consisted on how to purchase dantrolene (4), how to research MH susceptibility (3), and how to obtain additional information about the disease (8). For the general information, proposed solutions were, respectively: contact the customer service department (SAC) of the lab selling dantrolene in Brazil (Cristália: +55-11-0800 7011 918); seek MH outpatient clinic to schedule a visit (telephone +55-11-55719667); and visit Cedhima's website (MH section) at www. anestesiologia.unifesp. br. The additional information requested by the eight callers were: how to assemble a hospital kit of $\mathrm{MH}$; who may have $\mathrm{MH}$; which is the safe anesthesia for $\mathrm{MH}$; where to find literature on $\mathrm{MH}$ for school work; and, finally, if halothane exhaled by a pet dog after surgery could be dangerous for susceptible individuals to $\mathrm{MH}$. The first three information are available on Cedhima's MH section, while the fourth information initially recommended keeping the animal in the veterinary clinic during postoperative period and, subsequently, a consultation with MHAUS (Malignant Hyperthermia Association of the United States: www.mhaus.org.br) was done and it was suggested to follow the recommendation of the MHAUS consensus about the lack of risk, to susceptible individuals, associated with residual anesthetic in the operating room air, provided there is the necessary exhaustion. Table 1 shows the distribution of calls by caller's characteristic.

Among the seven patients with suspected $\mathrm{MH}$ acute episode, three calls came from the hospital that houses the Brazilian hotline service for $\mathrm{MH}$; afterwards, two of these patients underwent investigation and susceptibility to $\mathrm{MH}$ was confirmed. Given that 16,865 anesthetic procedures were performed at Hospital São Paulo (EPM/Unifesp) in 2009 (including anesthetics for surgeries and diagnostic procedures), the presence of two $\mathrm{MH}$ episodes would indicate, in this service, a frequency of 1.1:10,000. Of these, 8,906 were general anesthesia, which would imply a MH episode frequency of 2.2 per 10,000 general anesthesia cases in this service.

Considering the seven patients with suspected $\mathrm{MH}$ episode after reviewing the history and additional tests required, in two of them the episodes were not considered as $\mathrm{MH}$. One patient had not used triggering agents (halogenated or succinylcholine), and the event was later diagnosed as a reaction to fentanyl. The other patient had postoperative hyperthermia and sepsis was diagnosed.

All five patients whose episode was considered compatible with $\mathrm{MH}$ underwent anesthesia with halogenated anesthetics ( 2 with isoflurane, 3 with sevoflurane); one patient also received succinylcholine. This group consisted of four men and one woman, mean age 18 years (range 2-27). Surgeries performed were orthopedic (1), ENT (ears, nose, throat) surgery (1), gastrointestinal (2), and thoracic (1). The problems described in these five patients during the $\mathrm{MH}$ episode were, in order of frequency: tachycardia ( 5 patients: mean of $130 \mathrm{bpm}$, range of 120-140 bpm); increase in expired carbon dioxide (4 patients: mean of $70 \mathrm{~mm} \mathrm{Hg}$, range of $52-96 \mathrm{~mm} \mathrm{Hg}$ ); hyperthermia ( 3 patients: mean of $39.5^{\circ} \mathrm{C}$, range of $39-40^{\circ} \mathrm{C}$ ); acidemia (1 patient: $\mathrm{pH} 7.22$ ); rhabdomyolysis (2 patients: CPK 4,701-27,037 U.L-1); and choluria (1 patient). According to the clinical grading scale to assess the likelihood of $\mathrm{MH}^{8}$, these five $\mathrm{MH}$ episodes had a mean score of 28 points (range 18-43). Table 2 presents the clinical grading scale to assess the likelihood of $\mathrm{MH}^{8}$ and anesthetics used in five patients.

Relatives of two of the patients considered compatible with $\mathrm{MH}$ reported that deaths had occurred during anesthesia in other family members.

Table 1 Characteristics of Callers.

\begin{tabular}{ll}
\hline Characteristics & Number (\%) \\
\hline Anesthesiologist & $8(36 \%)$ \\
Intensivist & $1(4.5 \%)$ \\
Orthopedist & $1(4.5 \%)$ \\
Physician & $2(9 \%)$ \\
(specialty not specified) & \\
Nurse & $1(4.5 \%)$ \\
Pharmacist & $4(18 \%)$ \\
Graduate student (medicine) & $1(4.5 \%)$ \\
Patient & $3(14 \%)$ \\
Ignored & $1(4.5 \%)$ \\
Total & 22
\end{tabular}


Table 2 Clinical Grading Scale Score for MH Probability ${ }^{8}$ versus Anesthetics Used in Five Brazilian Patients.

\begin{tabular}{|c|c|c|c|c|}
\hline Score & Theoretical probability & $\begin{array}{l}\text { Theoretical risk of } \\
\text { MH }\end{array}$ & Patients and score $(\mathrm{n})$ & Triggering anesthetic \\
\hline 0 & Almost impossible & 1 & 0 & \\
\hline 3 to 9 & Unlikely & 2 & 0 & \\
\hline 10 to 19 & Somewhat less than likely & 3 & $\begin{array}{l}\text { Patient 1: } 18 \\
\text { Patient 2: } 18\end{array}$ & $\begin{array}{l}\text { Sevoflurane } \\
\text { Isoflurane }\end{array}$ \\
\hline 20 to 34 & Somewhat more than likely & 4 & Patient 3: 28 & $\begin{array}{l}\text { Sevoflurane + } \\
\text { succinylcholine }\end{array}$ \\
\hline 35 to 49 & Quite likely & 5 & $\begin{array}{l}\text { Patient 4: } 33 \\
\text { Patient 5: } 43\end{array}$ & $\begin{array}{l}\text { Isoflurane } \\
\text { Sevoflurane }\end{array}$ \\
\hline 50 or + & Almost certain & 6 & 0 & \\
\hline
\end{tabular}

Guidance to $\mathrm{MH}$ compatible individuals was done according to the informed characteristic of the episode and standardized treatment protocol ${ }^{1,2}$. In four patients, $\mathrm{MH}$ episode ceased with discontinuation of triggering halogenated agents and measures such as cooling ( 2 patients) and hyperventilation with $100 \%$ oxygen ( 2 patients); in one patient (number 3) dantrolene was administered. All five patients were monitored in the intensive care unit and recovered without sequelae; two of them were referred for evaluation and investigation at Cedhima (patients 2 and 4) and will be described in detail below.

Patient 2: male, aged 27 years, ASA I, with history of tumor mass in the left thigh, whose biopsy diagnosed alveolar sarcoma. The patient received four cycles of chemotherapy (ifosfamide and doxorubicin), which have been completed 10 months ago, and subsequently amputation was required of the left lower limb. The patient was later diagnosed with lung metastasis and underwent right pulmonary metastasectomy four months ago. Both previous surgeries were performed under combined/balanced general anesthesia, uneventful, and halogenated isoflurane was used in both surgeries.

Subsequently, a new pulmonary metastasectomy was indicated (now to the left), with balanced/combined general anesthesia induced with midazolam, fentanyl, propofol, and atracurium. Isoflurane (up to $1 \mathrm{MAC}$ ) in addition to epidural anesthesia were used for maintenance. After induction, the patient evolved to persistent and unexplained sinus tachycardia, normothermia, and maximum expired $\mathrm{CO}_{2}$ of $52 \mathrm{~mm} \mathrm{Hg}$ (Figure 1). Postoperatively, the patient developed diffuse myalgia and choluria. Serum creatine phosphokinase (CPK) levels were measured on the third postoperative day and showed a value of $27,037 \mathrm{U}^{-L^{-1}}$ (normal value 190 U.L.1), which raised the hypothesis of postoperative rhabdomyolysis due to $\mathrm{MH}$. The patient evolved without further complications; was discharged from the ICU on the sixth day, informed about his possible susceptibility to $\mathrm{MH}$, and referred to Cedhima's outpatient clinic.

On physical and neurological examination during outpatient evaluation, the patient presented diminished breathing sounds in the left hemithorax and left lower limb amputation

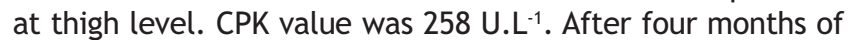
hospital discharge, the patient underwent right vastus lateralis muscle biopsy for in vitro muscle contracture test in response to halothane and caffeine. Two tests with halothane showed contracture $(0.24 \mathrm{~g}$ and $0.48 \mathrm{~g}$, concentration of $2 \%)$, which is consistent with positive results, indicating susceptibility to
MH. Histopathological examination of skeletal muscle showed mild subsarcolemmal mitochondrial proliferation. Since the $\mathrm{MH}$ episode, the patient had already undergone two lung metastasectomies under total intravenous anesthesia, uneventfully.

Patient 4: female, aged 23 years, ASA I, with history of left patella chronic dislocation since 11 years old after fall from own height. The patient had undergone three previous uneventful surgical procedures (varus osteotomy, femorodistal pseudo-arthrodesis, and medial patellofemoral reconstruction), all on the left side. In the preanesthetic evaluation, the patient denied significant family history.

Subsequently, the patient was admitted for revision of left femur osteosynthesis evaluation, and general anesthesia was chosen, given the time scheduled for the procedure. Concomitant epidural anesthesia was initially attempted; however, due to accidental dural puncture, this procedure was abandoned. General anesthesia was induced with sufentanil, propofol, and pancuronium, with isoflurane and sufentanil used for maintenance. After four hours of uneventful surgery, without apparent surgical reasons, the patient showed increased capnometric values (up to $66 \mathrm{~mm} \mathrm{Hg}$, confirmed with arterial blood gas, also showing respiratory acidosis); tachycardia (121 bpm); and

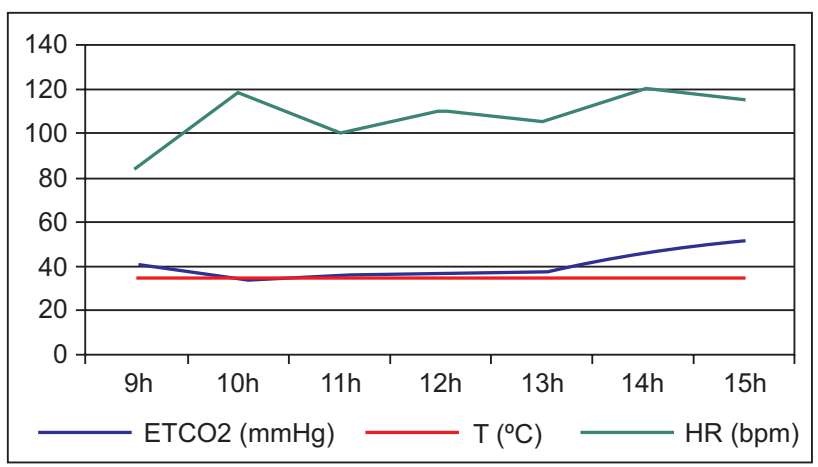

$\mathrm{ETCO}_{2}$ : end-tidal carbon dioxide; mmHg: millimeters of mercury; T: temperature; ${ }^{\circ} \mathrm{C}$ : degrees Celsius; HR: heart rate; bpm: beats per minute; h: hours.

Figure 1 Patient 2: $\mathrm{ETCO}_{2}$, Temperature, and Heart Rate during Intraoperative Period. 
temperature elevation (baseline: $36^{\circ} \mathrm{C}$, maximum reached $40^{\circ} \mathrm{C}$, intraesophageal temperature sensor). The diagnosis of malignant hyperthermia was then hypothesized by the anesthesiologist, and the proposed measures were taken ${ }^{1,2,7}$. The surgical team was notified of the suspected diagnosis and the maintenance anesthesia was replaced by exclusively intravenous injection of propofol via an infusion pump and opioid fentanyl, when necessary). Additionally, infusion of cold saline and hyperventilation with oxygen $100 \%$ was started, with improvement within minutes following these measures. After surgery and uneventful extubation in the operating room, the patient was transferred to the ICU for 48 hours. CPK showed progressive elevation from the surgery, with maximum of 4,701 U.L-1 , two days after surgery, but with gradual return to baseline. The patient was discharged on the sixth day after the procedure, asymptomatic, informed about the suspected susceptibility to $\mathrm{MH}$, and referred to Cedhima's outpatient clinic.

During outpatient evaluation, the patient reported a history of exhertion intolerance, with cramps, in addition to congenital clubfoot. She reported several changes in her family: son with inguinal hernia; father with pectus carinatum, clubfoot, and chronic patellar dislocation; paternal aunt and grandmother with chronic patellar dislocation; first-degree cousin who died during surgery. On physical and neurological examination, the patient presented short neck, bilateral ptosis, and arched palate. Serum CPK was increased at rest $(1,061$ U.L-1). Three months after discharge, she underwent right vastus lateralis muscle biopsy for in vitro muscle contracture test in response to halothane and caffeine. There was contracture in two tests with halothane $(3.6 \mathrm{~g}$ and $1.56 \mathrm{~g}$, concentration of $2 \%$; Figure 2 ) and two tests with caffeine $(2.92 \mathrm{~g}$ and $1.2 \mathrm{~g}$, concentration of $2 \mathrm{mmol}$; Figure 3 ) compatible with positive results, indicating susceptibility to $\mathrm{MH}$. Pathological examination of skeletal muscle showed sparse fibers with various changes, such as necrosis, hypertrophy, centralization or segmentation.

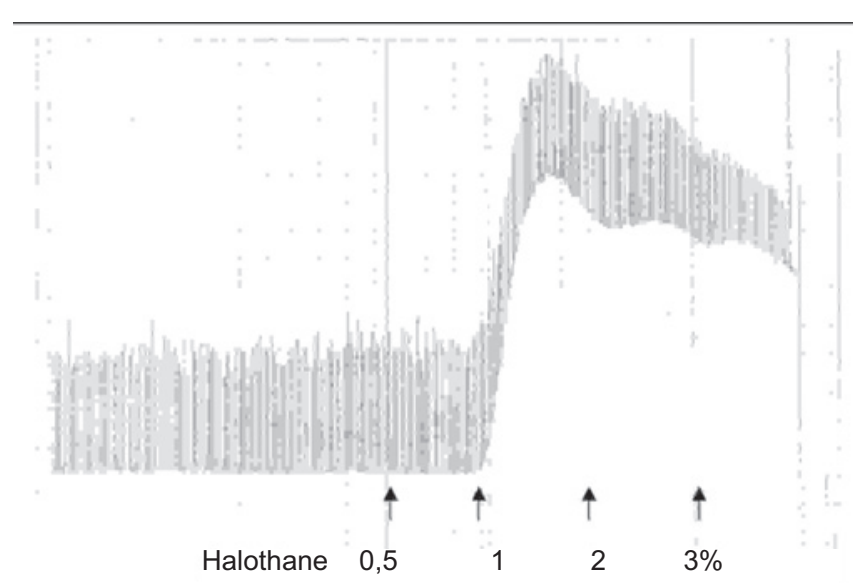

$\%$ : Percentage. Arrows indicate the time at which the drug was added.

Figure 2 In Vitro Muscle Contracture Test in Response to Halothane (patient 4).

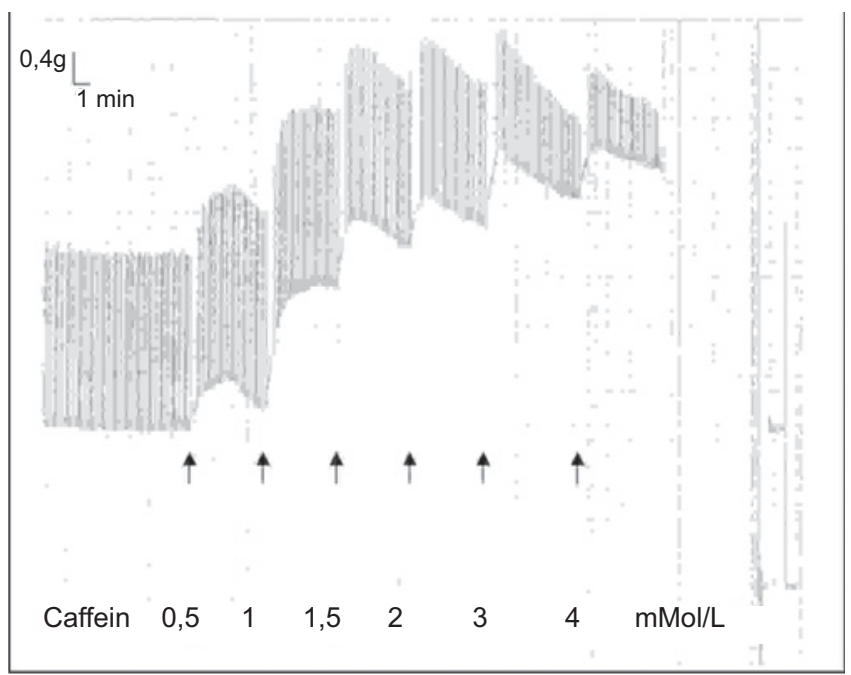

g: gram; min: minutes; mmol. $L^{-1}:$ millimoles per liter. Arrows indicate the time at which the drug was added.

Figure 3 In Vitro Muscle Contracture Test in Response to Caffeine (patient 4).

\section{Discussion}

Calls to MH hotline were mostly from the Southeast Region and within the State of São Paulo. This finding may be due to the fact that the hotline service is located in São Paulo and because there is specific legislation for $\mathrm{MH}$ in this state, which requires notification of the $\mathrm{MH}$ episodes and dantrolene availability ${ }^{11-14}$. On the other hand, the complete lack of calls from the states of Rio de Janeiro and Santa Catarina could be explained by the centralization of services related to $\mathrm{MH}$ in these states (Universidade Federal do Rio de Janeiro and the Universidade Federal de Santa Catarina, respectively) ${ }^{1,7}$.

However, it is more difficult to explain the lack of calls from the Northeast and Midwest regions, from Minas Gerais and Espírito Santo States, as well as a single call from the Northern region. With the increased level of suspicion, it is possible that more $\mathrm{MH}$ diagnoses will be made, as occurred in the hotline service for $\mathrm{MH}$. In the past, $\mathrm{MH}$ was believed as being exclusive to Caucasians, which has proven to be incorrect with the description of MH episode in BLACKS, Orientals, and Indians ${ }^{15-17}$. In Brazil, the initial impression that the $\mathrm{MH}$ genetic trait would be concentrated in European descendants in the south has also been disproved by genetic studies, such as the description of a patient from Minas Gerais who was compound heterozygous (i.e., an individual with two different mutations in their ryanodine receptor, each inherited from one of the non-consanguineous parents) ${ }^{18}$. This finding from the work of Kossugue et al. ${ }^{18}$ conforms the estimated frequency of the ryanodine gene mutation in ryanodine carriers, which could reach up to $1: 2000^{19}$. This prevalence would be much higher than the estimated rate for $\mathrm{MH}$ episode - explained by the fact that many mutation carriers are never anesthetized with triggering drugs and, even if exposed, they may not develop a MH episode, as occurred in patient 2 of this report ${ }^{20}$. 
Much of the calls were requests for information, which is understandable due to MH rarity, with characteristics of an orphan disease. Orphan diseases are rare and affect a small number of individuals and/or have no treatment that stimulates the interest of industry investments, diagnosis, and treatment ${ }^{21}$.

Regarding dantrolene issues, in Brazil there is a Resolution of the Federal Council of Medicine (Resolution CFM $1.802 / 2006)$, which includes dantrolene on the list of “drugs that should necessarily be available in any setting where anesthesia is used" ${ }^{22}$. Considering an individual weighing $70 \mathrm{~kg}$ and a loading dose of dantrolene $2.5 \mathrm{mg} . \mathrm{kg}^{-1}$, nine vials of dantrolene $20 \mathrm{mg}$ would be required for the first bolus. Because bolus is repeated until the $\mathrm{MH}$ episode is controlled and up to $10 \mathrm{mg} \cdot \mathrm{kg}^{-1}$ ( 4 boluses) may be needed to control it, 36 vials of dantrolene should be kept in stock. This stock must be immediately available to anesthesiologists, as the time to dilute dantrolene can reach 4 minutes per vial and the mortality rate is demonstrated to increase when the first dose is administered 30 minutes after the onset of the episode ${ }^{23,24}$. Furthermore, there is a need for options for quickly acquiring additional dantrolene, in case there is a need for more than $10 \mathrm{mg} . \mathrm{kg}^{-1}$ of dantrolene to control a episode, a need to continue treatment for 24-48 hours, and the increasingly common possibility of overweight patients.

MH differential diagnosis includes various conditions that may lead to hypercapnia (problems in the ventilation circuit), hypermetabolism (pheochromocytoma, thyrotoxic episode, exogenous intoxication with salicylates), and/or hyperthermia (iatrogenic heating, sepsis). Although $\mathrm{MH}$ may occur postoperatively, it is unlikely that fever alone characterizes $\mathrm{MH}^{25}$. Another cause for excluding $\mathrm{MH}$ diagnosis in hotline calls in 2009 was an isolated reaction characterized by muscle rigidity after opioid use, a rare event associated with high doses, which occurs during induction or recovery and may show improvement after naloxone or neuromuscular block ${ }^{26}$.

Regarding $\mathrm{MH}$ episode presentation in our country, there are similarities with those reported in other countries. The halogenated agents involved were sevoflurane and isoflurane. Keep in mind that all halogenated agents may cause $\mathrm{MH}$, even when the patient has not received succinylcholine ${ }^{27}$. There was a clear predominance of male $(80 \%)$, as well as young patients, similar to the recent revision by Larach et al. ${ }^{24}$, which reports $74.8 \%$ of men with mean age of 22 years. The higher frequency of episodes in men, a disease that has autosomal dominant inheritance (i.e., not sex-linked), has been explained by the greater muscle mass in males. The higher frequency in young people may be correlated with increased use of halogenated agents in this population.

We should emphasize that in the present report two families had a history of anesthetic problems that were not reported to the anesthesiologist before the procedure, which reinforces the importance of exhaustive investigation of any suggestive history during preoperative evaluation.

The fact that all five patients with an episode compatible with MH had a good outcome, even with only one of them receiving dantrolene, is unusual and cannot be considered representative of the reality in Brazil, as the hotline notification is voluntary. In the United States, where the frequency of MH episodes have been increasing, mortality rates due to $\mathrm{MH}$ vary between $1.4 \%$ and $22 \%$, even with all the available treatment ${ }^{28-30}$.
The non-use of dantrolene in some reports may be associated with difficulty in obtaining the drug in some locations or instant improvement of abortive's episode with discontinuation of halogenated agents. However, patients who do not receive dantrolene, even without presenting with cardiorespiratory arrest, are at risk for complications, such as liver failure or myalgia and rhabdomyolysis, as the case with patient 2 of this report ${ }^{24}$.

Regarding clinical features associated with susceptibility to $\mathrm{MH}$, several authors have reported osteoarticular changes (chronic dislocation, clubfoot), dimorphisms (cleft palate, ptosis, strabismus), and myopathies (central core myopathy). In this study, patient 4 illustrates this association, with a history of multiple dimorphisms and presence of osteoarticular changes over four generations ${ }^{1,7,17}$.

\section{Conclusions}

Considering Brazil as a whole, the number of calls to the hotline service for $\mathrm{MH}$ is still small for a one-year period and there is a large concentration in the Southeast region. Moreover, the frequency of calls was proportionally much higher in the hospital housing the hotline service, probably due to the continuing education programs developed there. Awareness of $\mathrm{MH}$ in Brazil needs to be increased, in addition to actions already implemented (regular insertion of $\mathrm{MH}$ theme in anesthesiology meetings; production of updated material, such as books and Brazilian guidelines for $\mathrm{MH}$, and development of electronic site for MH: http: / / www. unifesp. $\mathrm{br} / \mathrm{dcir} /$ anestesia/hipertermiamaligna/index.html).

\section{Financial Support}

Capes, CNPQ, Cristália, Fapesp.

\section{Acknowledgements}

We would like to thank all the health professionals and patients who helped with information.

\section{References}

1. Silva HCA, Tsanaclis AMC, Amaral JLG (Ed.) - Hipertermia maligna. $1^{\text {a }}$. ed. Rio de Janeiro: Atheneu, 2008.

2. Rosemberg H, Sambuughin N, Dirksen R - Malignant hyperthermia susceptibility. GeneReviews - NCBI Bookshelf 2010: 1-30.

Disponível em: http://www.ncbi.nlm.nih.gov/bookshelf/ br.fcgi?book=gene\&part=mhs.

3. Muniz VP, Silva HC, Tsanaclis AM et al. - Screening for mutations in the RYR1 gene in families with malignant hyperthermia. J Mol Neurosci, 2003;21(1):35-42.

4. Vainzof M, Muniz VP, Tsanaclis AM et al. - Does the A3333G mutation in the CACNL1A3 gene, detected in malignant hyperthermia, also occur in central core disease? Genet Test, 2000;4(4):383-6.

5. Pereira JB, Castro DL, Lucchesi NO - Hipertermia maligna durante cirurgia de estapedectomia. Rev Bras Anestesiol, 1975;25:3-12.

6. Ministério da Saúde - Sistema de Informações Hospitalares do SUS (SIH/SUS). Disponível em: www.Datasus.gov.br.

7. Amaral JLG, Silva HCA (Ed.) - Anais do V Simpósio Brasileiro de Hipertermia Maligna. Rev Neurociênc, 2005;13(3)Suplemento:194.

8. Larach MG, Localio AR, Allen GC et al. - A clinical grading scale to predict malignant hyperthermia susceptibility. Anesthesiology, 1994;80:771-779. 
9. Dubowitz, V - Muscle biopsy: a pratical approach. 2nd ed. London: Baillière Tindall, 1985, pp. 3-220.

10. Ellis FR, Halsall PJ, Ording $H$ et al. - A protocol for the investigation of malignant hyperpyrexia $(\mathrm{MH})$ susceptibility. $\mathrm{Br}$ J Anaesth, 1984;56:1267-1269.

11. Lei $\mathrm{n}^{\circ} 10.781$, de 9 de março de 2001. Diário Oficial, v.111, n. 170, 7/9/2001. Dispõe sobre a Política Estadual de Prevenção, Diagnóstico e Tratamento da Hipertermia Maligna - HM no Estado de São Paulo e dá providências correlatas.

12. Decreto 46.601, de 12 de março de 2002. Diário Oficial, v.112, n. 47, 13/3/2002. Dispõe sobre a Política Estadual de Prevenção, Diagnóstico e Tratamento da Hipertermia Maligna - HM.

13. Resolução SS-23, de 27 de fevereiro de 2004. Aprova Norma Técnica relativa às diretrizes para diagnóstico, tratamento, prevenção, notificação e investigação epidemiológica dos casos de hipertermia maligna. Diário Oficial, Poder Executivo, Seção I, São Paulo, 114(39), pp. 17-19, sábado, 28/2/2004.

14. Teixeira $P$ - Hipertermia maligna, legislação no Estado de São Paulo. Revista Neurociências 2005;13(3)(supl-versão eletrônica):21-25.

15. Parris WCV, Kambam J, Adkins B - Typical and atypical presentation of malignant hyperpyrexa in nonwhite patients. Anesth Prog, 1988; 35:208-211.

16. Wang YL, Luo AL, Tan G et al. - Clinical features and diagnosis for Chinese cases with malignant hyperthermia: a case cluster from 2005 to 2007. Chin Med J 2010;123(10):1241-1245.

17. Stamm DS, Aylsworth AS, Stajich JM et al. - Native American myopathy: congenital myopathy with cleft palate, skeletal anomalies, and susceptibility to malignant hyperthermia. Am J Med Gen, 2008;146A:1832-1841.

18. Kossugue PM, Paim JF, Navarro MM et al. - Central core disease due to recessive mutations in RYR1 gene: is it more common than described? Muscle Nerve, 2007;35(5):670-674.

19. Monnier N, Krivosic-Horber R, Payen JF et al. - Presence of two different genetic traits in malignant hyperthermia families: implication for genetic analysis, diagnosis, and incidence of malignant hyperthermia susceptibility. Anesthesiology, 2002;97(5):1067-1074.
20. Barbier M, Lafaye AL, Guerin R et al. - A case of malignant hyperthermia arising five hours after the beginning of anaesthesia with sevoflurane and after five uneventful surgical procedures. Ann Fr Anesth Reanim, 2009;28:983-987.

21. Denis A, Mergaert L, Fostier C et al. - Issues surrounding orphan disease and orphan drug policies in Europe. Appl Health Econ Health Policy, 2010;8(5):343-350.

22. Resolução CFM N $N^{\circ} 1.802 / 2006$. Dispõe sobre a prática do ato anestésico. Diário Oficial de 1 de novembro de 2006, Seção I, p. 102.

23. Kugler Y, Russell WJ - Speeding dantrolene preparation for treating malignant hyperthermia. Anaesth Intensive Care, 2011;39(1):84-8.

24. Larach MG, Gronert GA, Allen GC et al. - Clinical presentation, treatment, and complications of malignant hyperthermia in North America from 1987 to 2006. Anesth Analg, 2010;110:498507.

25. Halsall PJ, Ellis FR - Does postoperative pyrexia indicate malignant hyperthermia susceptibility? Br J Anaesth, 1992;68(2):209-210.

26. Roy S, Fortier LP - Fentanyl-induced rigidity during emergence from general anesthesia potentiated by venlafexine. Can J Anesth, 2003;50(1):32-35.

27. Glahn KP, Ellis FR, Halsall PJ et al. - Recognizing and managing a malignant hyperthermia crisis: guidelines from the European Malignant Hyperthermia Group. Br J Anaesth, 2010;105(4):417420.

28. Rosero EB, Adesanya AO, Timaran $\mathrm{CH}$ et al. - Trends and outcomes of malignant hyperthermia in the United States, 2000 to 2005. Anesthesiology, 2009;110(1):89-94.

29. Brady JE, Sun LS, Rosenberg $\mathrm{H}$ et al. - Prevalence of malignant hyperthermia due to anesthesia in New York State, 2001-2005. Anesth Analg, 2009;109:1162-1166.

30. Larach MG, Brandom BW, Allen GC et al. - Cardiac arrests and deaths associated with malignant hyperthermia in North America from 1987 to 2006: a report from the North American Malignant Hyperthermia Registry of the Malignant Hyperthermia Association of the United States. Anesthesiology, 2008;108:603-611. 